\section{A maternidade em contextos de vulnerabilidade social: papéis e significados atribuidos por pais e mães}

\author{
Ana Paula Benatti \\ Caroline Rubin Rossato Pereira \\ Dalila Carolina Moreira dos Santos \\ Ilana Lemos de Paiva
}

\section{RESUMO}

O presente estudo investigou o significado da maternidade vivenciada em contextos de vulnerabilidade social, por considerar que estes poderiam imprimir peculiaridades ao seu exercício. Participaram seis pais e seis mães de crianças com até doze anos incompletos, os quais se encontravam cadastrados em um Centro de Referência de Assistência Social (CRAS) de um município do interior do estado do Rio Grande do Sul. Os dados foram coletados através de um questionário sociodemográfico e de uma entrevista semiestruturada e foram analisados a partir da Análise de Conteúdo, tendo como referencial epistemológico a Teoria Sistêmica. Os resultados encontrados apontaram uma sobrecarga de papéis desempenhados pelas mães, tanto no que se refere à organização do ambiente doméstico quanto ao cuidado e educação dos filhos, sendo tal sobrecarga associada ao significado atribuído à maternidade no contexto investigado. Isso porque, para pais e mães, a mãe ideal ou a "boa mãe" era entendida como aquela que ocupa um lugar central na família, responsabilizando-se pelos afazeres domésticos, cuidado e educação dos filhos, principalmente no que se refere a práticas de controle e disciplina.

Palavras-Chave: Relações familiares; Maternidade; Famílias em Situação de Vulnerabilidade Social.

\section{ABSTRACT}

\section{Motherhood in contexts of social vulnerability: Roles and meanings attributed by fathers and mothers}

The present study investigated the meaning of motherhood experienced in contexts of social vulnerability, considering that these will have peculiarities to its performance. Six parents and six mothers of children until twelve years-old who were enrolled in a Centro de Referência de Assistência Social (CRAS) of a municipality in the state of Rio Grande do Sul participated. Data were collected through a Sociodemographic Questionnaire and a Semistructured Interview and were analyzed through Content Analysis, having the Systemic Theory as epistemological referential. The results showed an overload of roles played by the mothers, regarding the organization of the domestic environment and to the care and education of the children, and this was associated with the meaning of motherhood in the investigated context. That's because, to fathers and mothers, the ideal mother or the "good mother" was understood as someone that occupies a central place in the family, taking responsibility for the housework, care and education of the children, especially regarding the practices of control and discipline.

Keywords: Family Relationships; Motherhood; Families in Situation of Social Vulnerability.

De acordo com Correia (1998), o significado da maternidade varia de cultura para cul-

\section{Sobre os Autores}

A. P. B. https://orcid.org/0000-0001 5321-3104

Universidade Federal de Santa Maria, Santa Maria - RS benattianapaula@gmail.com

C. R. R. P.

http://orcid.org/0000-0001-98618391

Universidade Federal de Santa

Maria, Santa Maria - RS

carolinerrp@gmail.com

D. C. M. S

http://orcid.org/0000-0002-3821-

0447

Universidade Federal de Santa

Maria), Santa Maria - RS

dalilacarolinna@hotmail.com

I. L. P.

https://orcid.org/0000-0002-

3331-2890

Universidade Federal do Rio

Grande do Norte), Natal - RN

ilanapaiva@hotmail.com

\section{Direitos Autorais}

Este é um artigo aberto e pode ser reproduzido livremente, distribuído, transmitido ou modificado, por qualquer pessoa desde que usado sem fins comerciais. 0 trabalho é disponibilizado sob a licença Creative Commons CC-BY-NC 
tura e para cada mulher. Deste modo, sua vivência deve ser compreendida considerando-se ao menos dois componentes importantes, um componente cultural, que diz respeito à forma como as situações são compartilhadas e significadas socialmente e, o componente intrínseco, que se refere às características próprias da pessoa como, por exemplo, seus traços singulares. Portanto, não é possível atribuir significados e experiências universais acerca da maternidade, uma vez que os papéis de mãe, assim como de pai e de criança, sempre responderão, ao menos em parte, às exigências e aos valores dominantes de uma determinada sociedade.

Assim, a maternidade corresponde não apenas a um "acontecimento biológico, mas a uma vivência inscrita numa dinâmica sócio-histórica" (Correia, 1998, p. 366). Neste sentido, considera-se que o contexto social no qual a maternidade é vivenciada influencia de forma relevante no modo como a mãe desempenhará seu papel, assim como nas concepções e significados que ela atribuirá à sua condição de ser mãe. Portanto, pensar a maternidade em contextos de classe média e/ou média alta e em contextos de vulnerabilidade social implica pensar em realidades distintas, com peculiaridades e significados próprios. Por ser um país de grandes contrastes socioeconômicos, o Brasil ainda possui um grande número de pessoas vivendo em situação de pobreza e, até mesmo, abaixo da linha desta (IPEA, 2017).

0 conceito de vulnerabilidade social, o qual caracteriza o contexto social em que o presente estudo transcorreu, surgiu recentemente no Brasil e na América Latina (Nascimento, 2012, Fonseca, et al., 2013). Para além do fator econômico, a vulnerabilidade social corresponde a situações de fragilidade vivenciadas pelos indivíduos, (Janczura, 2012, Fonseca et. al, 2013, Cronemberger \& Teixeira, 2013), envolvendo uma ampla gama de variáveis como: o acesso às políticas públicas de saúde, educação e assistência social, condições de habitação, convivência familiar e comunitária, relações de vizinhança, entre outros (Hillesheim \& Cruz, 2008, Fonseca et al., 2013). Portanto, o termo vulnerabilidade social pode ser entendido como um estado transitório experienciado pelos indivíduos e/ou suas famílias, que, de maneira alguma, se restringe à condição de pobreza, ampliando-se, assim, o foco de atenção dos programas e serviços de Proteção Social.

Ao considerar o lugar ocupado pelas mulheres nas famílias brasileiras de modo geral, de acordo com dados do IBGE (2014), em 2010, as mulheres foram indicadas como responsável familiar em $37,3 \%$ dos lares brasileiros, sendo que o número aumenta para $39,3 \%$ na área urbana e diminui consideravelmente na área rural $(24,8 \%)$. Do to- tal de famílias cujo responsável familiar possuía cor preta ou parda $(49,9 \%)$, em $38,7 \%$ as mulheres eram as responsáveis pela família; entre as famílias monoparentais $(18,5 \%), 87,4 \%$ eram chefiadas por mulheres e do total de famílias com renda per capita até meio salário mínimo (30,1\%), $46,4 \%$ eram as mulheres as responsáveis. Dessa forma, esses dados indicam um número considerável de famílias tendo a mulher como responsável familiar, com maior predominância na área urbana, em famílias monoparentais, cujo responsável familiar possui cor preta ou parda e cuja renda per capita é inferior, as quais poderão constituir-se no público-alvo de programas e serviços de Proteção Social. Nesse sentido, considerando o atual número de mulheres e mães como pessoa de referência nas famílias brasileiras, associado à realidade de pobreza existente, como seria vivenciar a maternidade em tais situações/contextos? Como se desenvolve o papel materno e quais os significados atribuídos à maternidade nesses contextos?

Historicamente, tanto em contextos de classe média/ alta quanto nas camadas populares, a maternidade esteve tradicionalmente associada a estereótipos de gênero, sendo os cuidados domésticos e a criação dos filhos atividades consideradas como obrigatoriamente femininas (Sarti, 2011; Bossardi \& Vieira, 2015). Nas classes média e alta, todavia, essa concepção foi, gradualmente, sofrendo alterações, principalmente a partir da entrada da mulher no mercado de trabalho e da maior participação do pai na vida doméstica e dos filhos (Souza \& Ramires, 2006; Bossardi \& Vieira, 2015). Nas camadas populares, por sua vez, a maternidade parece manter-se mais atrelada a concepções tradicionais de gênero. Conforme Sarti (2011), as tarefas domésticas e o cuidado dos filhos continuam sendo prioritariamente desempenhados pela mãe e, na impossibilidade de fazê-lo, há o deslocamento desta responsabilidade para outras figuras femininas da família.

Consoante a tal, o estudo de Muñoz, et al., (2013), realizado com nove mães chilenas, assim como o de Cúnico e Arpini (2014), que investigou dez mulheres de periferia urbana de uma cidade do Rio Grande do Sul, identificaram sentimentos de sobrecarga, angústia e resignação em relação à maternidade vivenciada em contextos de vulnerabilidade social. Os sentimentos de angústia e resignação surgiram pelo fato de que tais mães não possuíam projetos para o futuro, vivendo o momento presente com incerteza, tendo em vista suas condições precárias de sobrevivência. Desta forma, entende-se que a sobrecarga relatada pelas mães reforça a importância da rede de apoio para auxiliá-las no exercício de seu papel. 
No que tange ao mundo do trabalho, ao considerar a realidade de mulheres de diferentes regiões do país, incluindo mães de classe média e moradoras de favelas do Rio de Janeiro (Almeida, 2007) e mães coletoras de material reciclável de uma cidade do Rio Grande do Sul (Wottrich \& Arpini, 2014), evidenciou-se em comum aos diferentes contextos de vida, o sentimento de culpa por parte das mães ao terem que se dividir entre o trabalho e o cuidado com os filhos. O primeiro estudo (Almeida, 2007), ainda, apontou uma diferença quanto ao significado do trabalho para as mães pesquisadas, sendo que, para as mães de classe média, o trabalho possuía um significado pessoal, vinculado à realização pessoal, enquanto que para as mães de camadas populares ele tinha a função de prover as necessidades básicas da família.

Em relação aos cuidados infantis, eles foram apontados por mães de comunidades de baixa renda de São Paulo (Martin \& Angelo, 1999) e do Rio de Janeiro (Almeida, 2007) como atribuição sua, devendo ser desempenhado por elas. Neste sentido, Wottrich e Arpini (2014) evidenciaram que a carência de recursos financeiros influenciou de forma significativa as concepções das muIheres acerca dos cuidados necessários à infância, sendo que as mães apresentaram narrativas ambivalentes acerca das estratégias utilizadas para a educação dos filhos. De um lado, elas enfatizaram o que consideravam ideal, ou seja, estratégias verbais e, por outro lado, descreveram o que consideravam possível e efetivo na educação dos filhos, o que correspondia, na visão delas, à coerção física. Todavia, as ações maternas que tinham o intuito de disciplinar os filhos estavam fundamentadas na noção de que elas eram as responsáveis por sua educação, devendo torná-los sujeitos "de valores".

Considerando os aspectos salientados, parte-se do pressuposto de que os contextos de vulnerabilidade social conferem significados diversos à maternidade, bem como oferecem desafios adicionais ao seu exercício, tendo em vista adversidades como a maior dificuldade para acessar os mínimos sociais, como alimentação, moradia e renda. Desta forma, considera-se fundamental que os profissionais que atuam junto às políticas públicas brasileiras possam dirigir um olhar cuidadoso para os significados atribuídos pelas próprias mães e pais acerca da maternidade em contextos de vulnerabilidade social e, assim, produzirem-se ações mais eficazes, que valorizem tanto o saber técnico-especializado, quanto o saber popular daqueles com os quais atuam, evitando a culpa- bilização das mães e famílias.

Visto que a inserção oficial do psicólogo junto ao Sistema Único de Assistência Social (SUAS) se deu a partir de 2006, quando foi incluído como membro nas equipes de referência dos serviços socioassistenciais (Brasil, 2006), compreende-se sua atuação nesse contexto como um campo ainda em desenvolvimento. Como desafio a esses profissionais, necessita-se romper com modelos tradicionais que consideram o ser humano como produto de fenômenos intrapsíquicos unicamente, buscando-se desenvolver metodologias de trabalho que considerem as influências do contexto social e da coletividade, ou seja, o homem enquanto ser biopsicossocial (Dimenstein, 2000, Costa \& Cardoso, 2010, Macedo \& Dimenstein, 2012, Senra \& Guzzo, 2012, Koelzer, et al., 2014). Visando contribuir para a atuação dos profissionais que trabalham com famílias, pretende-se que tal estudo aproxime as concepções de usuários e de profissionais quanto à temática da maternidade, uma vez que, segundo Dimenstein (2000), concepções antagônicas acerca de fenômenos psicossociais constituem-se em impasses para a atuação profissional e estão atrelados à desistência ou à não aderência dos usuários aos serviços.

Por fim, cabe salientar que não foram localizados estudos que abordem a visão dos pais (homens) acerca da maternidade. Assim, no presente estudo, além da perspectiva das próprias mães, este estudo procurará explorar essa lacuna da literatura, considerando que os papéis de gênero são construídos e mantidos a partir das relações sociais e das expectativas tanto das mães, quanto dos pais e da sociedade em geral. Desse modo, o presente estudo objetivou compreender o significado atribuído por mães e pais acerca da maternidade em contextos de vulnerabilidade social.

\section{MÉTODO}

\section{PARTICIPANTES}

Participaram desse estudo seis pais e seis mães de crianças com até doze anos incompletos, cujas famílias encontravam-se em situação de vulnerabilidade social e estavam cadastradas em um Centro de Referência de Assistência Social (CRAS) de um município de pequeno 
porte do interior do Rio Grande do Sul. A escolha dos participantes realizou-se através do critério de amostragem intencional, sendo que tais participantes foram definidos tendo em vista a inclusão de, ao menos, um pai ou mãe representativos de cada uma das seguintes configurações familiares: nuclear, recasada, monoparental e extensa. Tais configurações foram elencadas por acreditar que representam, ao menos em parte, a diversidade de arranjos familiares existentes entre as famílias brasileiras. Salienta-se, que o número de participantes (seis pais e seis mães) foi limitado tendo em vista o tamanho total do corpus a ser analisado a partir destas 12 entrevistas, de modo a não comprometer a qualidade e profundidade da análise (Gaskell, 2015).

Com relação às características sociodemográficas dos participantes, as mães possuíam idades entre 25 e 41 anos ( $M=33$ anos) e os pais possuíam idades entre 27 e 60 anos ( $M=43,5$ anos). A escolaridade dos participantes variou entre Ensino Fundamental incompleto e Ensino Médio incompleto, sendo que apenas dois dos 12 participantes apresentavam escolaridade superior ao Ensino Fundamental. No que se refere à ocupação, pode-se considerar variada. Por fim, os participantes apresentaram as seguintes configurações familiares: monoparental feminina simples, monoparental feminina extensa, nuclear simples, recasada e família convivente (Moreira, 2013, Carter \& McGoldrick, 1995). Em apenas um caso (M1 e P1) os participantes compunham um casal, ou seja, todos os demais eram provenientes de núcleos familiares diferentes.

Tabela 1. Perfil e Configurações Familiares das Mães

\begin{tabular}{|c|c|c|c|c|c|}
\hline Participante & Idade & Escolaridade & Ocupação & Com quem moravam & $\begin{array}{l}\text { Configuração } \\
\text { Familiar }\end{array}$ \\
\hline M1 & 33 & $\begin{array}{l}\text { Ensino funda- } \\
\text { mental incom- } \\
\text { pleto }\end{array}$ & $\begin{array}{l}\text { Serviços } \\
\text { Gerais }\end{array}$ & $\begin{array}{l}\text { Filhos ( } 10 \text { meses e } 15 \text { anos), } \\
\text { enteado ( } 14 \text { anos) } \\
\text { e esposo }\end{array}$ & Recasada \\
\hline M2 & 30 & $\begin{array}{l}\text { Ensino funda- } \\
\text { mental incom- } \\
\text { pleto }\end{array}$ & Do lar & $\begin{array}{l}\text { Filho (02 anos) } \\
\text { e mãe da mãe }\end{array}$ & $\begin{array}{l}\text { Monoparental } \\
\text { feminina extensa }\end{array}$ \\
\hline M3 & 29 & $\begin{array}{l}\text { Ensino funda- } \\
\text { mental com- } \\
\text { pleto }\end{array}$ & Do lar & $\begin{array}{l}\text { Filhos ( } 1,2,7 \text { e } 13 \text { anos) } \\
\text { e companheiro }\end{array}$ & Nuclear simples \\
\hline M4 & 41 & $\begin{array}{l}\text { Ensino funda- } \\
\text { mental incom- } \\
\text { pleto }\end{array}$ & Do lar & $\begin{array}{l}\text { Filho (11 anos), sobrinhos, pai } \\
\text { da mãe, irmã, } \\
\text { e cunhado }\end{array}$ & $\begin{array}{l}\text { Monoparental } \\
\text { feminina extensa }\end{array}$ \\
\hline M5 & 40 & $\begin{array}{l}\text { Ensino médio } \\
\text { incompleto }\end{array}$ & $\begin{array}{l}\text { Cuidadora de } \\
\text { Idosos }\end{array}$ & $\begin{array}{l}\text { Filhos ( } 2,13 \text { e } 18 \text { anos) e } \\
\text { sobrinhos (10 e } 12 \text { anos) }\end{array}$ & $\begin{array}{l}\text { Monoparental } \\
\text { feminina simples }\end{array}$ \\
\hline M6 & 25 & $\begin{array}{l}\text { Ensino funda- } \\
\text { mental incom- } \\
\text { pleto }\end{array}$ & $\begin{array}{l}\text { Serviços Ge- } \\
\text { rais (diarista) }\end{array}$ & $\begin{array}{l}\text { Filhas ( } 1,4,6 \text { e } 10 \text { anos) } \\
\text { e cunhada } \\
\text { Obs.: o companheiro encontra- } \\
\text { va-se em privação de liberdade }\end{array}$ & $\begin{array}{l}\text { Monoparental } \\
\text { feminina extensa }\end{array}$ \\
\hline
\end{tabular}


Tabela 2. Perfil e Configurações Familiares dos Pais

\begin{tabular}{|c|c|c|c|c|c|}
\hline Participante & Idade & Escolaridade & Ocupação & Com quem moravam & $\begin{array}{l}\text { Configuração Fami- } \\
\text { liar }\end{array}$ \\
\hline P1 & 38 & $\begin{array}{l}\text { Ensino funda- } \\
\text { mental completo }\end{array}$ & $\begin{array}{l}\text { Servidor } \\
\text { público }\end{array}$ & $\begin{array}{l}\text { Filhos ( } 10 \text { meses e } 14 \\
\text { anos), esposa e enteado } \\
\text { (15 anos) }\end{array}$ & Recasada \\
\hline P2 & 37 & $\begin{array}{l}\text { Ensino funda- } \\
\text { mental completo }\end{array}$ & Estoquista & Mãe & Família convivente \\
\hline P3 & 44 & $\begin{array}{l}\text { Ensino funda- } \\
\text { mental incom- } \\
\text { pleto }\end{array}$ & Pedreiro & $\begin{array}{l}\text { Filhos ( } 5 \text { e } 7 \text { anos) e } \\
\text { companheira }\end{array}$ & Recasada \\
\hline P4 & 27 & $\begin{array}{l}\text { Ensino funda- } \\
\text { mental incom- } \\
\text { pleto }\end{array}$ & $\begin{array}{l}\text { Servente de } \\
\text { Pedreiro }\end{array}$ & $\begin{array}{l}\text { Filho ( } 1 \text { mês) e compa- } \\
\text { nheira }\end{array}$ & Nuclear simples \\
\hline P5 & 60 & $\begin{array}{l}\text { Ensino funda- } \\
\text { mental incom- } \\
\text { pleto }\end{array}$ & Agricultor & $\begin{array}{l}\text { Filha ( } 6 \text { anos), enteado } \\
\text { (14 anos) e companheira }\end{array}$ & Recasada \\
\hline P6 & 27 & $\begin{array}{l}\text { Ensino médio } \\
\text { incompleto }\end{array}$ & Agricultor & $\begin{array}{l}\text { Filha ( } 1 \text { ano) e compa- } \\
\text { nheira }\end{array}$ & Nuclear simples \\
\hline
\end{tabular}

\section{DELINEAMENTO E PROCEDIMENTOS}

Trata-se de uma pesquisa de caráter qualitativo (Minayo, 2012), com delineamento transversal, exploratória e descritiva, descendente da pesquisa intitulada "Psicologia e Políticas Públicas: Saúde e desenvolvimento em Contextos de Vulnerabilidade Social". Essa pesquisa é desenvolvida com apoio do Programa Nacional de Cooperação Acadêmica (PROCAD), sendo composta pelos Programas de Pós-Graduação em Psicologia das seguintes universidades brasileiras: Universidade Federal do Rio Grande do Norte (UFRN), Universidade Federal de Santa Maria (UFSM) e Universidade de Brasília (UnB).

No que tange aos procedimentos para a execução desse projeto de pesquisa, inicialmente, o mesmo foi apresentado ao gestor da Secretaria de Desenvolvimento Social do município em questão, a fim de obter a Autorização Institucional para sua execução. Uma vez recebida a autorização, o projeto foi submetido à apreciação do Comitê de Ética em Pesquisa da [informação suprimida para não identificar os autores], sendo aprovado com o registro CAAE 65392217.4.0000.5346.
Após a aprovação do projeto pelo Comitê de Ética, foi solicitada aos técnicos do CRAS a indicação dos pais e das mães que estariam aptos a participar do estudo. Posteriormente, foi estabelecido contato telefônico com as famílias indicadas com o objetivo de apresentar-lhes a pesquisa e convidá-las a participar do estudo. Havendo o aceite dos participantes, foi agendado um horário com eles para a apresentação e assinatura do Termo de Consentimento Livre e Esclarecido e aplicação dos instrumentos. As entrevistas ocorreram de forma individual, com cada um dos participantes e foram gravadas em áudio para, posteriormente, serem transcritas na íntegra. O local utilizado para a coleta dos dados foi definido de acordo com a preferência dos participantes, podendo ocorrer numa sala do CRAS ou na residência destes.

\section{Instrumentos}

Na realização desta dessa pesquisa foram utilizados dois instrumentos, ambos construídos pelas pesquisadoras, sendo eles: um Questionário Sociodemográfico e uma entrevista semiestruturada intitulada Entrevista Sobre Parentalidade em Contextos de Vulnerabilidade So- 
cial. O primeiro foi utilizado com o objetivo de obter informações acerca das características gerais das participantes, tais como: idade, escolaridade, profissão, etc. A entrevista, por sua vez, abordou os seguintes tópicos: a) o papel da mãe na criação dos filhos: rotina familiar, educação dos filhos, cuidados diários com os filhos e relacionamento com os filhos; b) o significado da maternidade: importância da mãe para os filhos e para a família e a definição de maternidade ideal.

\section{ANÁLISE DOS DADOS}

Os dados foram analisados através da Análise de Conteúdo (Bardin, 1977), sendo as categorias temáticas elaboradas a partir do modelo aberto (Laville \& Dionne, 1999), ou seja, definidas após a coleta dos dados tendo em vista a frequência e/ou relevância dos conteúdos manifestados pelos participantes. Para tanto, duas autoras do presente estudo trabalharam em conjunto como juízas na definição das categorias e na vinculação das falas dos participantes às respectivas categorias. Cada juíza avaliou separadamente as entrevistas com vistas a propor as categorias temáticas e a associar as falas às categorias. Eventuais discordâncias quanto à categorização das falas foram sanadas por uma terceira juíza, também autora do presente estudo.

\section{RESULTADOSE DISCUSSÃO}

Considerando os conteúdos manifestados nas entrevistas das mães e dos pais, os resultados acerca dos significados da maternidade foram organizados de forma a contemplar três categorias temáticas, as quais serão apresentadas e discutidas a seguir: "Tudo o que um filho precisa ele vem pedir direto pra mãe": sobre o cuidado com os filhos, "Uma boa mãe não pode dar tudo": sobre controle e disciplina e "Será que eu vou conseguir?": sobre sustento financeiro e cuidados com a casa.

\section{“TUDO O QUE UM FILHO PRECISA ELE VEM PEDIR DIRETO PRA MÃE": SOBRE 0 CUIDADO COM OS FILHOS}

As mães entrevistadas entendiam que o cuidado é uma tarefa essencial do papel materno, sendo que ele envolve desde o aspecto físico até o aspecto emocional: "A mãe é pra tudo. A mãe é pra dar leite, a mãe é pra cuidar, a mãe é pra atender. Quando tá doente, é a mãe" (M2); "Porque tudo o que um filho precisa ele vem pedir direto pra mãe: ou está de mal, ou brigou, (...), vem pedir consolo pra mãe. Mãe é tudo, não tem explicação" (M3). Outro aspecto do cuidado refere-se à participação da rotina dos filhos: "Boa mãe é participar de tudo o que os filhos fazem, porque os filhos vão pro colégio, a mãe tem que participar, vão pra creche, tem que participar, estão em casa fazendo algum tema, tem que participar" (M3).

Os pais (homens) entrevistados também relacionaram o cuidado físico e emocional como componente do papel materno: "Amor. Principal coisa é amor mesmo (referindo-se à "boa mãe")" (P1); "Boa mãe também tem que estar ali pra cuidar dos filhos (...), na educação, na doença, tudo o que é coisa a mãe tem que estar ali pra auxiliar" (P2). Alguns dos pais entrevistados também afirmaram que em suas casas a mãe é a responsável por cuidar dos filhos: "A mulher fica arrumando o nenê pra levar pra creche (...). Sete horas ela chama o [nome do filho] (...) pra ir pro colégio (...), faz o café dele" (P1); “Ela atende: 'Mãe eu quero isso', 'mãe eu quero aquilo'. Vai atendendo, sempre está junto" (P5). 0 participante P5 ainda elogia o modo com sua esposa se preocupa em manter a saúde e o bem-estar dos filhos: "Deu febre, ela já está em cima (...), tem que ir no plantão, tem que ir lá no postinho para já ver o que está acontecendo. Nisso aí ela é muito enérgica. (...). Nisso é coisa de primeira mesmo" (P5).

Consoante, o estudo etnográfico de Bustamante e Trad (2005), realizado com sete casais de um bairro popular de Salvador (BA), identificou que os cuidados corporais para com os filhos eram percebidos como atribuição feminina, sendo que esses cuidados deveriam ser desempenhados pela mãe, de modo que o pai atuaria como um auxiliar ou ajudante da mãe. Da mesma forma, o estudo transversal de Falceto, et al. (2008), realizado em um bairro de classe média baixa da cidade de Porto Alegre, indicou que relações conjugais problemáticas e o fato da mãe não possuir um trabalho remunerado como fatores associados ao não envolvimento do pai nos cuidados de bebês.

A primazia da mãe no desempenho dos cuidados parentais esteve ligada, em alguns casos, ao fato de o pai não residir ou não manter contato com os filhos: "Quando eu engravidei a primeira vez, eu tinha 15 anos, eu pensava o que eu ia fazer pra criar a minha filha (...). E as outras, praticamente eu também criei sozinha, sozinha" (M6); "Depois que eu virei mãe tudo mudou, porque eu virei mãe e pai do meu filho ao mesmo tempo (...). Mas estou aí, fazendo meu papel de mãe e pai. Já que não tem pai, fica eu pelos dois" (M2). Em outros casos, o investimento do 
pai no trabalho e, consequentemente no sustento financeiro da família, fazia com que não estivesse presente e/ ou disponível para compartilhar de atividades diárias com os filhos: "Ele trabalha, e daí tem final de semana que também ele trabalha e daí as coisas (afazeres domésticos e cuidados com os filhos) ficam tudo por minha conta" (M3); "Eu trabalho o dia inteiro, daí ela trabalha duas vezes por semana. Então, ela tá mais presente do que eu. (...) Ela tem mais tempo de cuidar" (P1).

Neste sentido, Sousa e Guedes (2016) apontaram que, apesar de, atualmente, haver um aumento da participação da mulher no mercado de trabalho, tal mudança não esteve associada a uma equalização da divisão sexual do trabalho no país. Embora a mulher esteja mais ativa nos espaços públicos e no mercado de trabalho, a ela ainda compete a realização da maior parte do trabalho doméstico e tarefas laborais. Em contrapartida, mesmo com um aumento da participação do homem nos afazeres domésticos, a ele ainda é reservado o espaço produtivo de forma privilegiada.

As mães ainda expressaram, com relação ao cuidado dos filhos, ênfase especial no que se refere ao receio para com as vulnerabilidades presentes no contexto em que viviam, como exposição ao álcool e outras drogas: "Não deixo sair fora do portão de noite, porque é perigoso. Eu até vou saí dali da vila pra não tá perto" (M6); “Eu falo bastante nisso, que não é pra lidar com essas coisas (drogas). Que a gente mora ali no meio bem dizer. Às vezes, os filhos da gente, a gente cria de um jeito e pode dar outro, mas eu explico bastante pra eles como que é pra lidar com isso" (M3); "Não dá pra deixar, largar muito. Ainda mais essas coisa que tá acontecendo por aí na região (...). Assim, coisarada de droga" (M4). Incluindo também situações de vulnerabilidade no próprio ambiente familiar: "O meu pai bebe demais. Quando ele toca de beber, meu Deus. E quando o meu pai tá bêbado, daí eu não deixo (os filhos) ir (na casa dele)" (M6).

0 cuidado em evitar situações de vulnerabilidade no contexto social e no ambiente familiar não é algo próprio do contexto de vulnerabilidade social, podendo existir em outros contextos socioeconômicos. Todavia, pode-se pensar que ambos os contextos - familiar e social - podem tanto constituir-se como rede de apoio à maternidade, bem como um fator de risco para ela. Isto porque à medida que algumas tarefas parentais podem ser compartilhadas com outros membros da família, e mesmo da vizinhança, deixando a mãe menos sobrecarregada, estes esses contextos passam a atuar como fonte de apoio ao exercício da maternidade. Por outro lado, estes contextos podem constituir-se em um fator de vulnerabilidade ao apresentar certos problemas e fragilidades, como o uso de drogas e a violência. Dessa forma, a preocupação em evitar situações de vulnerabilidade para os filhos pode ser uma nova fonte de estresse às mães, para a qual elas necessitam desenvolver estratégias de enfrentamento.

\section{“Uma boa mãe não pode dar tudo": sobre controle e disciplina}

As mães entrevistadas acreditavam ser uma atribuição do papel materno educar e disciplinar os filhos: "Uma boa mãe não pode dar tudo. (...) Porque a gente quer dar mais coisas que a gente não tinha, né. Então, a gente tem que saber, também, dizer não" (M5); "Eu acho que o papel da mãe é cuidar, educar e estar sempre presente, jamais abandonar um filho como o pai faz" (M2); "Boa mãe educando seu filho. É, não digo fazer todas as vontades, também, porque daí fazem de gato e sapato a mãe e o pai, mas amando e respeitando" (M1). Desta forma, as mães demonstraram ser responsáveis pela educação dos filhos utilizando, para tanto, estratégias como o diálogo, o castigo e a punição física: "Olha, conversando, eu acredito que conversando se ajeita tudo. Senão, se precisar a gente dá uma xingada, também" (M5); "Eu boto de castigo no quarto se teimar comigo (...). Converso com elas e não deixo fazerem o que elas querem, daí" (M6); "Quando não obedecem, às vezes tomam umas varadas. Eu dou mesmo. Eu chamo lá e daí a gente conversa, quando não é pra tá batendo toda hora" (M3).

Percebe-se o investimento das mães na educação dos filhos e a oscilação entre práticas educativas indutivas e coercitivas. A esse respeito, Wottrich e Arpini (2014), ao investigarem mães coletadoras de material reciclável de uma cidade do interior do Rio Grande do Sul, identificaram uma dicotomia entre práticas idealizadas (estratégias verbais) e aquelas consideradas eficazes (coerção física). Consoante, Zamberlan (2008) e Marin, et al., (2012) indicaram que mães de camadas socioeconômicas pauperizadas tendiam a valorizar mais as práticas de controle, obediência e disciplina dos filhos, ao passo que em famílias de classe média e média-alta os pais tendiam a valorizar e a estimular a autonomia da criança.

A participante $\mathrm{M} 6$ relatou, também, o desejo de exercer sua maternidade de forma diferente da vivenciada com sua própria mãe, indicando a necessidade de romper com práticas consideradas inadequadas para a criação dos filhos: "Eu não quero ser, sabe, mãe durona. Aquelas mães que qualquer coisa estão xingando. É que eu fui criada assim, então eu não quero pros meus filhos. $\mathrm{E}$ o que eu não tive, eu também quero dar pra elas" (M6). 
A afirmação de M6, no que se refere a não repetir algumas das experiências que teve com sua mãe, em sua infância, é melhor explicada por Bolze e Crepaldi (2015) ao trabalharem o conceito de descontinuidades da transmissão intergeracional. As descontinuidades ocorrem quando essa transmissão é interrompida, o que ocorre através da interação entre mecanismos mediadores e moderadores. Para as autoras, através das relações íntimas desenvolvidas com pessoas significativas - amigos, cônjuge, terapeuta, entre outros - é possível promover um rompimento nos padrões comportamentais e relacionais do adulto, aprendidos durante sua infância, e desenvolver novos repertórios, que possuam sentido e significado para $\mathrm{o}$ adulto.

Ainda referente ao controle e disciplina das crianças, os pais entrevistados relataram diferentes compreensões sobre o papel da mãe na educação dos filhos, ou seja, que ambos os pais (pai e mãe) são responsáveis pela educação e limites dos filhos (P1 e P4), que apenas a mãe é a responsável (P2 e P5), que a mãe é a responsável, todavia, os filhos não a obedecem (P3), que a mãe é a responsável na ausência do pai (P6). 0 pai $\mathrm{P} 1$, discorrendo acerca da educação dos filhos, mencionou a necessidade em haver concordância de ideias entre pai e mãe para que seus papéis não sejam desautorizados frente aos filhos: "Não adianta tu viver ali em família, mas viver sempre desunido: um educa assim, outro quer educar assim. Então, tem que ser meio unido, balançando as conversas" (P1).

Entretanto, apesar de alguns pais (homens) indicarem uma divisão igualitária entre pai e mãe no que se refere às práticas de controle e disciplina dos filhos, a mãe foi considerada pelos pais como figura central na educação dos filhos: "Primeira coisa é educar bem os filhos" (referindo-se às funções da mãe) (P2); "É tarefa da mãe cuidar deles (crianças), também ajudar a gente a cuidar, não deixar (os filhos) fazerem coisa errada" (P3); "Isso é a mãe que dá pros filhos, dá as regras e vai explicando como tem que ser como não é, o que é bom o que é ruim" (P5). Estes resultados vão ao encontro do proposto por Zamberlan (2008), que encontrou que em famílias provenientes de contextos socioeconômicos vulneráveis, a mãe era, geralmente, a figura mais envolvida com o cuidado dos filhos, sendo que, em sua pesquisa, a mãe foi indicada como a responsável pela educação dos filhos em $80 \%$ das 75 famílias estudadas. Contudo, conforme Cúnico e Arpini (2014), para as mães de camadas populares que constituíam famílias monoparentais e educavam seus filhos sozinhas, o pai ainda era percebido como a principal figura de autoridade. Desta forma, a manutenção da autoridade e do respeito por parte das mães pode se constituir como um desafio frente à educação dos filhos.

Além disso, verificou-se a importância dada pelas mães à transmissão de valores, tais como educação, respeito e honestidade: "Eu acho que o essencial, de momento, é educação, porque educação é o que faz a pessoa ir adiante, se não ensinar agora, de grande vai seguir os outros, vai fazer coisa errada" (M2); "O mais importante não lidar com droga, nem com brigar no colégio, nem roubar, que é o principal, isso eu falo bastante pra eles. Primeiro lugar o estudo" (M3); "Primeiro lugar, a honestidade e, né, falar a verdade. (...). Então: a verdade, não mexer nas coisas dos outros. Não gosto que mexam. Nunca! Não aceito isso, né." (M5).

A preocupação expressa pelas mães entrevistadas em transmitir valores aos filhos contraria a lógica, ainda presente no senso comum, que associa pobreza com periculosidade. Como resquício dos antigos Códigos de Menores de 1927 e 1979, tem-se a noção de que as famílias pobres não são aptas a criar e educar suas crianças. Apesar do enorme avanço advindo da promulgação do Estatuto da Criança e do Adolescente (Brasil, 1990), as famílias pobres continuam a ser alvo de desqualificação e culpabilização por problemas de fatores de ordem socioeconômica e política. Tal visão pode estar na base de intervenções acríticas, consideradas como prática de criminalização da pobreza (Nascimento, et al., 2008, Hillesheim \& Cruz, 2008, Nascimento, 2012).

\section{"Será que eu vou conseguir?": sobre sustento finan- ceiro e cuidados com a casa}

Além dos cuidados com os filhos, foi possível identificar a preocupação das mães com a manutenção financeira da família: "É eu que pago aluguel, é eu que pago a água, eu que pago a luz, fazer rancho (compras no mercado). Faz dois meses que eu não sei nem o que é ir no mercado. Daí não sobra. Tudo é eu. Tudo, tudo, tudo. Desde algum remédio pra comprar, é eu" (M6); "Até esse mês que passou, era tudo comigo. Vou ser bem sincera. Tudo, tudo, tudo. (...) Graças a Deus, sempre me virei, sempre trabalhei" (M5). Entre as duas mães que residiam com os companheiros, uma delas possuía emprego remunerado e relatou dividir as responsabilidades financeiras: "Os gastos a gente divide entre dois, eu e ele (companheiro)" (M1). Tal preocupação, deve ser lembrada, dava-se em um cenário de baixa escolaridade, empregos instáveis e com baixa remuneração. Além disso, para as mães que não possuíam emprego, sua renda mensal familiar provinha de benefícios socioassistenciais de transferência de renda e da doação e compartilhamento da renda de outros membros da família. 
Ainda com relação ao papel materno, percebeu-se que o mesmo era permeado por um forte sentimento de angústia. Para M6, essa angústia referia-se às privações econômicas pelas quais a família passava: "Sabe, eu me sinto uma péssima mãe, na verdade, quando eu não tenho pra dar nem comida pra elas (filhas). Daí, eu me sinto derrotada. Eu me sinto uma péssima mãe. Daí, eu fico nervosa, fico pensando: 'Que que eu vou fazer?"' (M6). Para M5 o sentimento associava-se ao exercício da maternidade como um todo: "Isso, de noite, eu fico pensando: 'Será que eu estou sendo uma boa mãe? Será que eu vou conseguir?'. Às vezes eu fico pensando. Eu tenho essas coisas na minha cabeça. Isso me dói" (M5).

A responsabilidade das mães no sustento financeiro das famílias, sendo, em alguns casos a única fonte para tal, rompe com as concepções tradicionais acerca dos papéis materno e paterno. Ao descrever os papéis de gênero em famílias pobres da periferia paulistana, Sarti (2011) estendeu-os aos papéis parentais, indicando que caberia à mulher o cuidado com a casa e os filhos, e ao homem o sustento financeiro e a transmissão da moral familiar. 0 presente estudo aponta para uma importante alteração nesse padrão, tendo a mulher agregado ao seu papel a manutenção financeira da família.

Com relação aos cuidados com a casa, ou seja, as tarefas domésticas, houve um consenso entre os pais (homens) de que cabia à mãe a organização do ambiente doméstico: "A faxina e organização da casa é minha esposa (...). A minha esposa que limpa, faz comida, lava roupa. Isso é com ela" (P6); "Uma boa mãe (...) colabora com a gente. Faz que nem a minha companheira: ela faz o serviço de casa, me ajuda no de fora, mas é uma boa mãe. Tu chega, tem uma roupa limpa, uma comida. Eu acho que é o dever dela. Assim é uma boa mãe. Daí o cara chega e não precisa se preocupar com essas coisas" (P5); "Cuidados com a casa, isso não me preocupo, porque ela faz e bem, nunca deixa faltar nada pra elas (filhas)" (P2).

No que diz respeito às atribuições maternas, a partir do olhar das mães entrevistadas, o conteúdo mais enfatizado em suas falas referiu-se à responsabilidade para com o ambiente doméstico: "Cuidar a roupa dele (do fiIho), a comida, tudo. É funções que a gente tem. Manter ele sempre limpo, a casa tudo limpa. Essa que é a função, não deixar faltar nada" (M4); "Principalmente nas roupas (...), na parte de comer (referindo-se às responsabilidades da mãe)" (M1). A participante M1 ainda demonstrou a centralidade que a mãe ocupa na família e no ambiente doméstico: "A mãe é tudo numa casa, meu Deus. Porque tudo depende da mãe. Tu precisa de uma coisa é a mãe. Tu precisa de outra coisa é a mãe" (M1).
A esse respeito, o estudo de Jablonski (2010), realizado com 20 membros de casais heterossexuais de classe média identificou que as mulheres, inseridas no mercado de trabalho, arcavam com uma dupla jornada de trabalho, sendo que o homem não compartilhava de forma igualitária a divisão das tarefas domésticas. Todavia, esse achado não foi associado à maior existência de conflito entre os casais, conforme esperado pelo pesquisador. Para ele, esta divisão desigual quanto ao trabalho doméstico é fortemente influenciada por questões tradicionais de gênero, indicando que estereótipos, tanto em relação aos papéis de gênero quanto aos papéis parentais, estão presentes nos diferentes níveis socioeconômicos.

Importante ressaltar, ainda, o significado implícito à maternidade, expresso na fala de P5, de modo que ser "boa mãe" não é apenas estar voltada às necessidades dos filhos, mas também à casa e ao marido. Parece, portanto, que pelo fato de ser mãe, a mulher possuiria atrelada à sua identidade a característica do cuidado, ou seja, como se a maternidade a tornasse apta para cuidar das pessoas: das crianças, dos maridos, dos idosos.

\section{CONSIDERAÇÕES FINAIS}

Com relação ao papel materno vivenciado em contextos de vulnerabilidade, verificou-se a existência de um sentimento de sobrecarga, tendo em vista as múltiplas tarefas que as mães desempenham em tais contextos. Pais e mães foram consoantes ao afirmarem que em suas famílias as mães eram mais presentes no ambiente doméstico que os pais, sendo as responsáveis pelo cuidado e pelo controle e disciplina dos filhos, sendo, em alguns momentos, a tarefa educativa dividida com o pai. Para os pais (homens) entrevistados, a mãe devia ocupar um lugar central na família, sendo capaz de educar e cuidar dos filhos, além de cuidar do próprio marido. Também eram compreendidas como parte das atribuições maternas a responsabilidade ou a contribuição para com o sustento financeiro e a organização doméstica.

Dessa forma, pode-se pensar que a sobrecarga advinda da multiplicidade de papéis desempenhados pelas mães está associada ao significado atribuído à maternidade, ou seja, de que a "boa mãe" é responsável por "tudo" numa família. Essa ideia favorece à manutenção de um padrão tradicional de gênero e pouco estimula a participação do pai no cuidado com os filhos e com a casa. Embora alguns participantes indicassem o compartilhamento das tarefas de cuidado e educação dos filhos entre pai e mãe, essas responsabilidades ainda re- 
caíam majoritariamente sobre as mães.

Para as mães entrevistadas, além das funções tradicionais referentes ao papel materno, somavam-se a responsabilidade para com o sustento financeiro e o desempenho da autoridade familiar, contrariando as concepções tradicionais acerca dos papeis parentais. Acredita-se que, em parte, isso se devesse ao fato de a maioria das mães constituírem famílias monoparentais femininas, sendo elas o único adulto responsável pela família. Por outro lado, ressalta-se que o fato de o pai não residir com a família não permite a ele eximir-se de seu papel junto aos filhos, tanto no que se refere aos cuidados e à educação, como em seu sustento financeiro e material.

Frente a isso, cabe refletir sobre o modo como homens e mulheres estão concebendo suas responsabilidades parentais em famílias heteronormativas. Parece haver uma naturalização do lugar da mãe como principal responsável pelos filhos, sem que haja um questionamento acerca da ausência do pai no contexto doméstico. Com isso, não se defende a manutenção das famílias nucleares como modelo hegemônico de configuração familiar, mas sim a responsabilização dos homens (pais) pelo cuidado de seus filhos, independentemente de residirem com eles ou não. Infelizmente, parece haver um longo caminho a trilhar a fim de modificar as concepções de gênero que associam maternidade ao cuidado dos filhos, desincumbindo os homens de tal tarefa. No caso dos homens, os cuidados com os filhos, parecem ainda atrelados à relação conjugal estabelecida entre o pai e a mãe, que, uma vez, rompida, rompe também o elo parental.

Dessa forma, os achados desse estudo podem servir como base para a prática do psicólogo com famílias no âmbito da Assistência Social. Importante ressaltar para o significado da maternidade em contextos de vulnerabilidade social, em que a mãe, muitas vezes, pode sentir-se sobrecarregada e sozinha no exercício de seu papel, o que pode vir a afetar sua saúde mental e, consequentemente, a saúde emocional dos próprios filhos. Nesse sentido, a atuação profissional deve visar o fortalecimento dos papéis parentais, bem como da rede de apoio disponível às famílias para que elas consigam executar suas funções. Além disso, faz-se necessário promover espaços para a discussão de papéis e estereótipos de gênero para com a população usuária destes serviços, flexibilizando tais papeis e incluindo o homem/pai, e outros cuidadores, no exercício da parentalidade.

Um cuidado ao considerar os resultados desse estudo refere-se ao fato de ele não se propõe representativo de toda a população proveniente de contextos de vulne- rabilidade social. Os participantes eram residentes de um município de pequeno porte do estado do Rio Grande do Sul. Apesar de oferecer reflexões importantes acerca da maternidade em contextos de vulnerabilidade, ressalta-se que, ao entrar em contato com uma comunidade em especial, os profissionais precisam conhecer as representações que o grupo específico possui acerca dos papéis sociais desempenhados nas famílias. Tais representações dizem respeito a fatores locais como cultura, clima, história e características de vulnerabilidade.

Além disso, o estudo não foi exaustivo quanto à variedade de configurações familiares existentes em nossa sociedade. Embora tenham sido acessadas todas as configurações familiares propostas nos critérios de inclusão do estudo - nuclear, recasada, extensa e monoparental sabe-se que existe uma diversidade muito grade de arranjos familiares, os quais possuem peculiaridades próprias merecendo, assim, ser contemplados em novos estudos científicos.

\section{DECLARAÇÃO DA CONTRIBUIÇÃO DOS AUTORES}

Certificamos que todos os autores participaram suficientemente do trabalho para tornar pública sua responsabilidade pelo conteúdo. A contribuição de cada autor pode ser atribuída como se segue: os autores 1 e 2 participaram da redação do artigo de modo geral; a autora 3 participou na análise dos dados; a autora 4 foi responsável pela revisão do artigo, assim como por parte da discussão dos resultados.

\section{DECLARAÇÃO DE CONFLITOS DE INTERESSE}

Os autores declaram que não há conflitos de interesse no manuscrito submetido.

\section{REFERÊNCIAS}

Almeida, L. S. de (2007). Mãe, cuidadora e trabalhadora: as múltiplas identidades de mães que trabalham. Revista do departamento de Psicologia - UFF, 19(2), 411-422. https://doi.org/10.1590/s0104-80232007000200011

Bardin, L. (1977). Análise de Conteúdo. Edições Setenta.

Brasil, Estatuto da Criança e do Adolescente (1990). Lei 8069, de 13 de julho de 1990. Dispõe sobre o Estatuto da Criança e do Adolescente e dá outras providências. http://www.planalto.gov.br/ccivil_03/leis//8069.htm. 
Bolze, S. D. A. \& Crepaldi, M. A. (2015). O pai e seus relacionamentos familiares: uma perspectiva intergeracional. In E. R. Goetz \& M. L. Vieira (Orgs). Novo pai: percursos, desafios e possibilidades (pp 31-43). Juruá.

Bossardi, C. N. \& Vieira, M. L. (2015). Ser mãe e ser pai: integração de fatores biológicos e culturais. In E. R. Goetz \& M. L. Vieira (Orgs.). Novo pai: percursos, desafios e possibilidades (pp 15-30). Juruá.

Bustamante, V. \& Trad, L. A. B. (2005). Participação paterna no cuidado de crianças pequenas: um estudo etnográfico com famílias de camadas populares. Cadernos de Saúde Pública, 21(6), 1865-1874. https:// doi.org/10.1590/s0102-311×2005000600036

Carter, B. \& McGoldrick, M. (1995). Constituindo uma família recasada. In $\mathrm{B}$. Carter \& $\mathrm{M}$. McGoldrick. As mudanças no ciclo de vida familiar: uma estrutura para a terapia familiar ( $2^{\mathrm{a}}$ ed., .pp 344-370). Artmed.

Correia, M. de J. (1998). Sobre a maternidade. Análise Psicológica, 3(16), 365-371.

Costa, A. F. de S. \& Cardoso, C. L. (2010). Inserção do Psicólogo em Centros de Referência de Assistência Social - CRAS. Gerais: Revista Interinstitucional de Psicologia,3(2), 223-229.

Cronemberger, I. H. G. M. \& Teixeira, S. M. (2013). Famílias vulneráveis como expressão da questão social, à luz da política de assistência social. Informe Econômico, 1(1), 17-26.

Cúnico, S. D. \& Arpini, D. M. (2014). Família e monoparentalidade feminina sob a ótica de mulheres chefes de família. Aletheia, 43(44), 37-49.

Dimenstein, M. (2000). A cultura profissional do psicólogo e o ideário individualista: implicações para a prática no campo da assistência pública à saúde. Estudos de Psicologia, 5(1), 95-121. https://doi.org/10.1590/ s1413-294x2000000100006

Falceto, O. G., Fernandes, C. L., Baratojo, C. \& Giugliani, E. R. J. (2008). Fatores associados ao envolvimento do pai nos cuidados do lactente. Revista de Saúde Pública, 42(6), 1034-1040. https://doi.org/10.1590/s003489102008000600009

Fonseca, F. F., Sena, R. K. R., Santos, R. L. A. dos, Dias, O. V. \& Costa, S. de M. (2013). As vulnerabilidades na infância e adolescência e as políticas públicas brasileiras de intervenção. Revista Paulista de Pediatria, 31(2), 258-264. https://doi.org/10.1590/s010305822013000200019
Gaskell, G. (2015). Entrevistas individuais e grupais. In M. W. Bauer \& G. Gaskell (Orgs.). Pesquisa qualitativa com texto, imagem e som: um manual prático. (13a ed), Vozes.

Hillesheim, B. \& Cruz, L. R. da (2008). Risco, vulnerabilidade e infância: algumas aproximações. Psicologia \& Sociedade, 20(2), 192-199. https://doi.org/10.1590/ s0102-71822008000200006

Instituto de Pesquisa Econômica Aplicada [IPEA] (2017). Radar IDHM 2015. Minas Gerais: Fundação João Pinheiro. http://www.atlasbrasil.org.br/2013/data/rawData/RadarIDHM_VERSAO_Final.pdf

Instituto Brasileiro de Geografia e Estatística [IBGE] (2014). Estatísticas de Gênero: uma análise dos resultados do Censo Demográfico 2010. https://biblioteca. ibge.gov.br/visualizacao/livros/liv88941.pdf.

Jablonski, B. (2010). A divisão de tarefas domésticas entre homens e mulheres no cotidiano do casamento. Psicologia, Ciência e Profissão, 30(2), 262-275. https:// doi.org/10.1590/s1414-98932010000200004 Janczura, R. (2012). Risco ou vulnerabilidade social? Textos e Contextos, 11(2), 301-308.

Koelzer, L. P., Backes, M. S. \& Zanella, A. V. (2014). Psicologia e CRAS: reflexões a partir de uma experiência de estágio. Gerais: Revista Interinstitucional de Psicologia, 7(1), 132-139.

Laville, C. \& Dionne, J. A. (1999). Construção do Saber: manual de metodologia da pesquisa em Ciências Humanas. Artmed.

Macedo, J. P. \& Dimenstein, M. (2012). O trabalho dos psicólogos nas políticas sociais no Brasil. Avances em Psicologia Latinoameicana, 30(1), 182-192.

Marin, A. H., Piccinini, C. A., Gonçalves, T. R. \& Tudge, J. R. $H$. (2012). Práticas educativas parentais, problemas de comportamento e competência social de crianças em idade pré-escolar. Estudos de Psicologia, 17(1), 0513.

Martin, V. B. \& Angelo, M. (1999). A organização familiar para o cuidado dos filhos: percepção das mães em uma comunidade de baixa renda. Revista Latinoamericana de Enfermagem, 7(4), 89-95. https://doi. org/10.1590/s0104-11691999000400012

Minayo, M. C. de S. (2012). Análise qualitativa: teoria, passos e fidedignidade. Ciência e Saúde Coletiva, 17(3), 621-626. https://doi.org/10.1590/s141381232012000300007 
Moreira, M. I. C. (2013). Novos rumos para o trabalho com famílias. São Paulo: NECA - Associação dos Pesquisadores de Estudos e Pesquisas sobre a Criança e o Adolescente. http://www.neca.org.br/wp-content/ uploads/novos $\% 20$ rumos $\% 20$ para $\% 200 \% 20$ trabaIho\%20com\%20familias

Muñoz, L. A., Sanchez, X., Vollrath, A. \& Bonatti, C. (2013). Vivenciando a maternidade em contextos de vulnerabilidade social: uma abordagem compreensiva da fenomenologia social. Revista Latinoamericana de Enfermagem, 21(4), 1-7.

Nascimento, M. L. do, Cunha, F. L. da \& Vicente, L. M. D. (2008). A desqualificação da família pobre como prática de criminalização da pobreza. Psicologia Política, 7(14), 1-17.

Nascimento, M. L. do (2012). Abrigo, pobreza e negligência: percursos de judicialização. Psicologia \& Sociedade, 24(spe), 39-44. https://doi.org/10.1590/s010271822012000400007

Sarti, C. A. (2011). A família como espelho: um estudo sobre a moral dos pobres. ( $7^{\mathrm{a}} \mathrm{ed}$.) Cortez.

Senra, C. M. G \& Guzzo, R. S. L. (2012). Assistência Social e Psicologia: sobre as tensões e conflitos do psicólogo no cotidiano do serviço público. Psicologia e Sociedade, 24(2), 293-299. https://doi.org/10.1590/s010271822012000200006
Sousa, L. P. de \& Guedes, D. R. (2016). A desigual divisão sexual do trabalho: um olhar sobre a última década. Estudos Avançados, 30(87), 123-139. https://doi. org/10.1590/s0103-40142016.30870008

Souza, R. M. de \& Ramires, V. R. R. (2006). Família e famílias. In R. M. de Souza \& V. R. R. Ramires. Amor, casamento, família, divórcio... e depois, segundo as crianças (pp 9-23). Summus.

Wottrich, S. H. \& Arpini, D. M. (2014). Cuidados necessários à infância: um estudo com mães coletadoras de material reciclável. Temas em Psicologia, 471-482. https://doi.org/10.9788/tp2014.2-16

Zamberlan, M. A. T. (2008). Ambientes domiciliares de famílias de baixa renda de área urbana: aspectos físicos e psicossociais. In M. A. T. Zamberlan \& Z. M. B. Alves. Interações familiares: teoria, pesquisa e subsídios à intervenção. ( $2^{\mathrm{a}}$ ed., pp 81-109), EDUEL.

Data de submissão: 09/06/2018 Primeira decisão editorial: 08/03/2019 Aceite em 05/10/2019 